\title{
A Hybrid Matryoshka and a Monastery
}

\section{Arms Control in the Era of Turbulence}

\author{
Konstantin V. Bogdanov
}

\author{
Konstantin V. Bogdanov, PhD in Engineering \\ Primakov National Research Institute of World Economy and International Relations, \\ Moscow, Russia \\ Center for International Security \\ Senior Research Fellow \\ ORCID: 0000-0002-5922-0791 \\ SPIN RSCI: 7056-8209 \\ Researcher ID: D-4116-2019 \\ Scopus Author ID: 57211334497 \\ E-mail:cbogdanov@imemo.ru \\ Address: 23 Profsoyuznaya Str., Moscow 117997, Russia. \\ DOI: $10.31278 / 1810-6374-2021-19-3-116-136$
}

\section{Abstract}

The post-bipolar world order, transitional in nature, lacks an established set of institutional norms and rules that would provide a place for arms control in the general system of international security. Many aspects of the world order that directly affect the arms control architecture have already changed, and this factor largely destructs existing arms control regimes. With the current world order in transition, which combines elements of the old order and new factors and interdependencies, it would be reasonable to take a hybrid approach to arms control where a well-structured and legally binding core addressing nuclear risks would be accompanied by flexible application of more liberal formats, making it possible to strengthen and develop periphery areas that were previously not covered by the relevant rules or lost them due to the cancellation of relevant agreements. This 
approach could preserve the disintegrating regimes by using more flexible means of substitution and modernize the core by establishing and improving arms control regimes in previously uncovered areas.

Keywords: arms control, international security, multilateral disarmament, nuclear weapons, post-bipolar world.

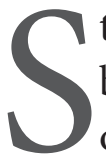

tatements about the crisis of the arms control regime have become commonplace in works studying the current system of international relations. While expert views on the causes and prerequisites of this crisis are more or less compatible (although differing in their interpretation and focus), arms control prospects cause substantial disagreements.

Foreign researchers voice a wide range of opinions on the modern arms control system. Some of its advocates call for preserving and strengthening it as a possible drive for normalizing relations between nuclear powers (Neuneck, 2019; Wolfsthal, 2020), while others suggest enhancing its binding nature in order to reduce the likelihood of nuclear war (Tertrais, 2010). Efforts are made to find ways to preserve the arms control architecture and develop it further, including through multilateralization (Bin, 2011; Cimbala, 2017; Legvold, 2018; Zhao, 2020), and objective problems that prevent further progress on the customary track are analyzed (Brooks, 2020). Skeptics are also quite active; they view arms control as a set of obsolete restrictions which in some cases negatively affect strategic stability and regional deterrence (Ford, 2013), or even as an obstruction to preventing a big war (Kroenig, 2013). So, they propose enhancing rather than reducing the role of nuclear capabilities for the sake of sustainable nuclear deterrence (Colby, 2018). There are even some who consistently deny any benefits of arms control and go further by claiming that it is harmful in its current form (Schneider, 2019).

The problem is actively discussed by Russian experts as well, eliciting an equally wide range of opinions. A large amount of work has been published, describing in detail negative consequences of the 
collapse of the arms control system, calling for its modernization and detailing possible practical ways of doing so (Arbatov, 2019; Rogov, 2020). Specifically, some authors suggest further reducing nuclear weapons (Dvorkin, 2017), developing multilateral formats, and expanding their scope (Arbatov, 2020). Many experts critically analyze the dynamics of bilateral Soviet/Russian-American arms control, the reasons for its decline in the last twenty years (Batyuk, 2018), and current difficulties that complicate strategic stability negotiations (Leontyev, 2019). The discussion is fueled by critical views on the very concept of bilateral control and statements questioning its relevance in the new military-political situation (Karaganov and Suslov, 2019). These debates are taking place against the background of an expressly negative, especially in view of the dramatic degradation of relations between Russia and the West in the past decade, attitude towards disarmament and arms control among domestic hardliners (for example, see Aladin et al., 2013), who particularly criticize existing agreements as undermining Russia's national security (Vildanov, 2012).

A significant part of the narrative is devoted to arms control as an objective reality, a kind of background for placing the authors' assessments and making plans for the future. Naturally, almost sixty years of arms control as we know it (since the Moscow Treaty of 1963 that banned nuclear weapon tests in the atmosphere, outer space and under water) have created, simply due to its scale and inertia, a large overhang of ideas and formed different schools of thought, a special philosophy and views on how the international security system can and should evolve. This is evidenced by how often the parties (whether arms control advocates or critics) use historical precedents from the Cold War era or the disarmament period immediately after it as their argument.

It seems right and even fair to try to find common ground for such different positions by studying the underlying reasons, motives, and concerns, and eventually testing the hypothesis of possible compatibility of the proposed solutions. Can there be arms control that would take into account both the need for a clear verifiable limitation of destabilizing systems and the obvious institutional "loosening" 
of the system of international relations? This is especially important amid mounting changes in the modern world order, where uncertainty increases, the images of a possible future multiply, and present-day instability is easily explained by criticizing the decisions that not so long ago were considered "cornerstones" of international security.

\section{CONTROL IS THE SOLUTION}

The history of arms control goes back centuries. One can recall the prohibition of Greek fire, attempts to limit the use of crossbows, and measures to determine the laws of war before and immediately after World War I. However, arms control began to play a truly important role in the system of international security priorities only after the creation and proliferation of nuclear weapons and their long-range delivery systems-a unique phenomenon that can potentially "turn the chessboard."

A classic interpretation of arms control and its differences from more narrowly understood disarmament was given in 1961 by Thomas Schelling and Morton Halperin. They defined it as "all the forms of military cooperation between potential enemies in the interest of reducing the likelihood of war, its scope and violence if it occurs, and the political and economic costs of being prepared for it" (Schelling and Halperin, 1961, p. 2).

For all its breadth, this definition is directly related to the peculiarities of the current system of international security and, therefore, the implementation of arms control in practice always refers to the current state of affairs in this area. In plain words, control means solving an urgent problem in specific conditions. It can even be assumed that a developed and complex arms control system may be more characteristic of an established and structured world order, such as the last two decades of the Cold War. Conversely, creating and maintaining such a system during a transition to a new world order is a much more difficult task.

The basic features of the bipolar world order that influenced the classical arms control are as follows (see, including Bogaturov, 2003; Utkin, 2005; Nikitin, 2018): 
- a rigid world system made up of two camps engaged in antagonistic ideological confrontation with each other (implying completely or largely mutually exclusive images of their future) as well as with "third countries" that had to build their policies in the contrasting context of confrontation between the USSR and the U.S. even despite their non-alignment status;

- a symmetric feeling of the "habitual Other": each bloc viewed the other as the main opponent and as a coordinate system for evaluating its own actions, seriously considering long-term prospects of competition with it in military-strategic, political, economic, scientific, technical, and cultural spheres, studying its strategic culture as a particularly significant phenomenon and maintaining a narrow but permanent security dialogue, despite recurring periods of "thaw" and "frost" in bilateral relations;

- concentration of nuclear capabilities in the two opposing blocs, moreover, in the hands of two superpowers: the "central deterrence" of the Soviet Union and the U.S. was the backbone of the international security system and incarnated the principle of strategic stability based on mutually assured destruction;

- a significant and even excessive number of deployed nuclear weapons and the corresponding doctrines substantiating their inevitable massive use in the event of a large-scale war between the two blocs, which created a fair "amount of fear" in the minds of decision makers;

- a probable course and nature of hostilities forecast by the parties, envisaging a rapid escalation of a conflict into an intense large-scale inter-bloc war (mainly in Europe), accompanied by the active use of non-strategic nuclear weapons in order to guarantee the destruction of targets in the theater of war, as well as by the use of chemical weapons.

The arms control regimes that meet these conditions have gone through certain stages of evolution. Having limited the quantitative race of strategic delivery vehicles and having linked the logic of strategic stability to tough restrictions on the creation of missile defense systems 
in the early 1970s, the Soviet-American process stalled as the nuclear arsenals grew immensely due to the deployment of MIRVed missiles and inconsistencies in strategic cultures. ${ }^{1}$ From the late 1970s until the 1990s, the main task of strategic arms control was to defuse a dangerous destabilizing situation that had allowed the parties to build up hard-target kill capabilities and treat the matching scenarios of massive selective nuclear attacks as realistic (see detailed discussion of this issue in the chapters devoted to the USSR and the U.S. in Krepon, Wheeler and Mason, 2016). At the very end of the Cold War, the launch of a large-scale nuclear disarmament process led to parallel progress on other tracks.

This period is characterized by the dominance, firstly, of the nuclear factor in arms control, and, secondly, of bilateral binding formats. This was due to the arms control priorities stemming from the above definition: the main task was to prevent a nuclear war between the two blocs' hegemons, understood as an inevitable catastrophe for the entire humankind. It was not until the very end of the Cold War, when the Soviet Union and the United States had solved pressing issues of nuclear disarmament (INF Treaty in 1987 and START-1 Treaty in 1991) and noticeably mended their bilateral relations, that years of discussion on the prohibition of chemical weapons, restrictions on the deployment of conventional weapons, and confidence-building measures regarding each other's military activity led to the conclusion of important multilateral, legally binding agreements: the Treaty on Conventional Armed Forces in Europe (1990), the Treaty on Open Skies (1992), and the Chemical Weapons Convention (1993).

The post-Cold-War world order is a transient phase, a temporary transformational phenomenon, which so far does not have an established definition in political science. The notorious "unipolar moment" (Krauthammer, 1990) or "pluralistic unipolarity" (Bogaturov, 2003) had ended by the mid-2000s and are not quite relevant to the

\footnotetext{
For differences between the parties in how they interpret the essence of nuclear deterrence and its stability, which contributed to the creation of significant counterforce capabilities at that time, see, for example, Snyder, 1977; Hines, 1995. For the security dilemma arising from the exaggeration of counterforce capabilities of the enemy amid a lack of information about its advanced programs, see Podvig, 2008.
} 
point at issue. The term a 'multipolar' (or 'polycentric') world promoted by the Russian school of thought as well as the "community of shared destiny for all humankind" promoted by China refer more to the desirable end result of this transition rather than to its essence.

Nevertheless, in the "post-bipolar" world order, there are certain features that are important from the point of view of arms control dynamics (Inozemtsev and Karaganov, 2005; Anthony, 2018; Arbatov, 2018):

- the growing rivalry between the great powers is not ideological as the "struggle of systems," which it was during the Cold War, but is a derivative of competition for the resources of the global world and for the right to determine regulatory norms within one system that is more or less uniformly understood and accepted by all parties involved in this race;

- the system itself has become much more complex: instead of two clearly defined camps, amorphous groups of interdependent powers have emerged, unevenly developed and equipped with tangible military-strategic capabilities; the influence of previous leaders is steadily decreasing, while a number of booming states, which in the past were invariably classified as the Third World, are gaining more and more opportunities to significantly affect international security (including through the nuclear factor);

- the transient nature of the present world order and the growing competition for resources within a single global system are undermining the viability of long-term military-political alliances based on a common vision of the future and shared values, and provoke the creation of flexible ad hoc coalitions, which resolve specific international security problems opportunistically, thus negatively affecting the institutional consolidation of the world order (Cold War of all against all) in the long term;

- the structure, the size, and the combat capabilities of the deployed strategic offensive arms groupings still define the logic of "central deterrence" along the Russia-U.S. axis, but the horizontal proliferation of nuclear weapons, which began in the 
second half of the Cold War, has facilitated a transition from quantity to quality: there have emerged systems of regional nuclear deterrence, which are completely disregarded by the classic "equations" of strategic stability, but which affect it; in addition, the likelihood of WMD and radioactive materials falling into the hands of non-state actors has increased, thus creating conditions for catastrophic terrorism;

- the reduction, to almost zero, of the likelihood of a large-scale world war and deep cuts in nuclear weapons have breathed a new life into the concept of their limited use either in the form of a "counter proliferation" strategy or in the form of "signal strikes" and "demonstrative actions" in the interests of intra-war bargaining;

- the transformation of ideas on what possible military conflicts will look like has, on the one hand, reduced the role of nuclear weapons (due to the rapid development of high-precision conventional weapons combined with increased intelligence capabilities, targeting and situational awareness) and on the other hand, has extremely complicated warfare due to the "entanglement" of nuclear and non-nuclear components (strike and command, control, and communications systems; see Acton et al., 2017); "multi-domain" doctrinal principles that contribute to the rapid escalation of local conflicts, in particular through the space and cyber domains; and the emergence of completely new weapons and military technologies that are not covered by existing agreements.

All these processes pushed the transformation of the usual "strategic stability" 2 into broader and multifactorial "strategic security" (Petrovsky, 2004), including, but not limited to, previous patterns. The post-bipolar world is hybrid in nature: it still combines certain

\footnotetext{
2 Construed as a configuration of offensive arms groupings that reduces or eliminates incentives for delivering the first nuclear strike, understood at that time (late 1980s) as massive and disarming. For details, see the "Joint Statement on Future Negotiations on Nuclear and Space Arms and Further Enhancing Strategic Stability” of June 1, 1990 (Yurkin, 1990, p. 335).
} 
elements of the previous world order with fundamentally new factors and relationships. This determines an integrated but equally hybrid approach to arms control ${ }^{3}$ at a time when we believe it will have to provide for:

- adhering to basic intrusive and legally binding agreements that ensure the overall stability of the military-political environment and the basic level of confidence (maximum restoration, preservation and modernization of the current core of arms control, primarily related to the reduction of nuclear risks);

- reducing uncertainty in the perception of the situation and intentions of opponents and, thereby, reducing the risk of an arms race and the outbreak of war due to miscalculations, which can be achieved through proactive and permanent discussion of strategic security issues, an open exchange of concerns and the development of recommendations on confidence-building and transparency measures, including multilateral formats (maintaining and developing infrastructure for strategic dialogue of appropriate scope and composition);

- preserving, at least partially and temporarily, arms control regimes that are disintegrating due to the changing military and political situation by shifting the focus to the development of realistic political commitments in these areas and a declarative framework if legally binding agreements are not possible at this stage (flexible replacements for de facto non-viable agreements for the transitional period until new treaties are concluded);

- combining creative application of all these measures to reduce security threats that were previously absent and/or not so high on the agenda, and for which there are no adequate instruments in the arms control toolkit (developing the "untapped periphery" of strategic security and moving from developed bilateral practices towards multilateral approaches).

Hybrid approaches were widely considered about twenty years ago (see, for example, Potter, 2001, p. 14) as an alternative means of promoting Russian-American control over offensive arms after the signing of the so-called START III Framework Agreement (START III) by Boris Yeltsin and Bill Clinton in Helsinki in 1997. 


\section{FROM THE CORE TO THE PERIPHERY}

The logic of military-technical development is asymmetric. Some historical eras may come when a certain package of technologies is developed (as was the case with the "empires of gunpowder" in the East or with the colonial activity of European powers at the very end of the 19th century), but the opposite is wrong: the change of eras cannot annul existing military-technical factors.

Nuclear weapons, as a special dominant phenomenon that completely rearranged both international relations and views on warfare after 1945, did not avoid this logic. The main "equations" of strategic stability during the Cold War-the principle of approximate parity in offensive capabilities in all three forms of their combat use, the resilience of retaliatory strike forces against the enemy's preventive attack, the elimination of the "use-it-or-lose-it" funnel in crises, and destabilizing massive deployment of defensive weapons-are now often considered self-evident. But there were times when these "cornerstones" caused fierce disputes and protests.

The Cold War is over, but nuclear forces produced by it are still there despite deep cuts. They are tied up by "equations" that form the basis of strategic arms control. Military-strategic capabilities turned out to be more stable and enduring than the era that engendered them and even the political regimes that created them. The same logic applies to verification mechanisms. None of the new destructive factors undermining the stability of nuclear deterrence between Russia and the United States overturns the fact that this nuclear deterrence must be formalized in an appropriate way so as to reduce the risk of old factors coming back into play. Under the current precarious conditions, when political confidence between Moscow and Washington is at its all-time low, abandoning existing regimes will only bring the parties back to the tasks they have been negotiating since the late 1960s, accelerate the arms race, and, more importantly, increase the likelihood of an unintended escalation in crisis.

The lack of trust not only complicates the achievement of new legally binding agreements, but it also increases their value in comparison with the more liberal formats of agreements (according to Ronald Reagan's "trust but verify" formula). This creates some motivation for 
maintaining the arms control core focused on reducing nuclear risks and preventing an arms race through "central deterrence." The Treaty on the Non-Proliferation of Nuclear Weapons (NPT) is the ideological basis of this core. With the previous system of agreements falling apart, a practical basis is needed. It should be provided, first of all, by the direct successor to the New START Treaty with regard to strategic offensive capabilities, as well as, possibly, by a set of new agreements addressing specific key problems of strategic stability that can be adopted in parallel.

The specific composition of such agreements is beyond the scope of this article. We will only note that further cuts in deployed strategic nuclear warheads are no longer so relevant in comparison with the parties' mutual desire to significantly expand the scope of agreements. The U.S. would like to put all types of nuclear warheads (including nonstrategic and non-deployed ones) and new types of Russia’s strategic weapons under control, while Russia is more interested in limiting high-precision long-range weapons (conventional and nuclear) and in getting U.S. concessions on missile defense.

The current situation makes it extremely difficult to work out viable agreements if they are not based on intrusive verification or at least legally binding. On the other hand, this also limits the applicability of the method: excessive expansion of the scope will turn negotiations into a Tower of Babel with an unclear outcome, while such a radical architecture of the one and only agreement will cause problems with its ratification by parliament (even if only in the United States). A possible solution would be dividing negotiations into different tracks, for example, a separate agreement on missile defense that will not be directly related to START, but will nevertheless help improve the overall situation. Such an agreement could provide for additional transparency in the exchange of data on ABM development plans, including the demonstration of intercept flight tests to the opposite side, as well as the prohibition of testing and deployment of certain future systems, such as space-based interceptors, for an adequate period of time (10-15 years) with a possible extension.

Attempts to make such agreements multilateral only complicate things. This becomes particularly evident when the parties have neither 
relevant experience of making such agreements in the past nor the developed practice of exchanging views on sensitive security issues. Without such experience, it is impossible to move forward either on multilateral tracks (for example, in the Russia-U.S.-China triangle or as part of the five NPT nuclear-weapon states) or outside "central deterrence" (India-Pakistan and India-China). However, the incomplete process of developing new rules of the game in the transitional world order, high uncertainty about the future and concerns for one's own security increase sensitivity to risks and threats (often exaggerating them, although this cannot be stated for sure while being inside the process, but only post factum).

All this brings us to one of the potentially important infrastructural functions of arms control during the transitional period: it can be called the "monastery principle." In the early Middle Ages, the institution of monasteries, among other things, performed the most important function of preserving, understanding and passing over generations written knowledge that proved useful during the next rise of European civilization. In our case, this means, above all, saving the culture of permanent strategic dialogue as one of the most important gains of Soviet-American arms control process-the desire and ability to hear the concerns of the counterparty (not necessarily following them), look at the situation with the partner's eyes and analyze how he perceives threats to his security. ${ }^{4}$ This reduces the likelihood of miscalculations during planning due to misinterpretation of the counterparty's intentions and actions, and this also contributes to the search for a viable negotiation compromise. We can already see that this culture was badly damaged in the 2010s, when the parties practically stopped full-scale substantive negotiations, limiting themselves to political and propaganda statements in the press and social media.

Such an institution is all the more important for getting prepared to deal with a wider range of negotiators, who will inevitably bring in their own distinct and very different strategic cultures. Even the

A widespread joke of the late Cold War period said that experienced Soviet and American negotiators knew each other's positions and arguments so well that they could swap places and continue to "play" negotiations for the opposite side.

VOL. $19 \bullet$ No.3 0 JULY - SEPTEMBER $\bullet 2021$ 
narrow Soviet-American experience shows that before the parties learn to hear each other, it can take many years of continuous mutual "lecturing" at the negotiating table. There can be no intrusive and legally binding agreements without such mutual tuning of language and communication; it is even less likely that they can be reached in one go in a multilateral format without step-by-step preparations.

It is quite possible that it will take a lot of time and effort to build regulatorily very liberal but at the same time broad multilateral formats, allowing them to exist at the expense of "supporting structures" secured by bilateral legally binding agreements. For example, the issue of unverifiable declaring or even "freezing" of the total number of nuclear warheads can probably be solved with the help of political declarations of the five nuclear-weapon states (subsequently expanded to some of the unofficial nuclear powers). At the same time, it would make sense to address more complex and intrusive issues of strategic stability within the narrow U.S.-China-Russia triangle, including an "unclosed" format, that is, two parallel bilateral agreements that involve the United States. This would split the agenda and ensure selective involvement, without complicating the negotiation of positions.

Similarly, some control processes, which have been going strenuously, could be structured as well. For example, two barely compatible approaches towards preventing an arms race in outer space (banning specific systems/technologies and banning certain intentions) could be split between two parallel tracks: a legally binding agreement and a politically binding code of conduct, respectively.

Some multilateral legally binding agreements have come down to us from the previous global thaw, even though not all of them are in good shape. It would be premature to expect them to remain active and function effectively in their original form, notwithstanding changes. In such cases, it would be realistic to talk about the political restatement of the parties' intentions in the new situation, perhaps abandoning some of the previous obligations and procedures, if they obviously impede constructive practical work to reduce risks.

Such proposals have been made in recent years regarding a possible transformation of the 1972 Biological Weapons Convention regime 
towards a more liberal interpretation of its norms requiring decisions to be adopted by consensus in order to intensify the practical work of the parties concerned, that is, facilitate the movement towards a flexible set of biological disarmament regimes (Littlewood, 2018). Similar processes, as one can judge, are getting underway now in the 1981 Convention on Certain Conventional Weapons regime, whereby interested parties are trying, through parallel initiatives, to break the deadlocks in the practical discussion of the problem of explosive weapons in populated areas (EWIPA) (Davis, 2020, pp. 496-499). However, we can also see that such steps do not always produce positive results as evidenced by the growing paralysis of the 1993 Chemical Weapons Convention regime and the continued politicization of the Organization for the Prohibition of Chemical Weapons and its use as an arena and a tool in the struggle of great powers for the attribution of attacks involving toxic substances.

This process can look like a rollback, a weakening of regimes, and a declining effectiveness of their implementation procedures, which is true to some extent. However, if the choice is not between more or less stringent control regimes, but between the presence of at least some coordinated restrictions and their complete absence, the situation looks completely different.

A striking example is the gradual death of the CFE Treaty, which by the time of ratification had already been implanted with a time bomb that allowed further existence of two military blocs in Europe. It was not fully removed even by the Agreement on the Adaptation of the CFE Treaty, signed in Istanbul in 1999 (affecting it ratification that became a complete failure). So the treaty, for the most part still de facto fulfilled by the parties, is "effectively dead" as a system of legal measures, and there is no reason to expect its speedy and painless restoration in the previous binding multilateral form. However, conventional arms control and predictability of military activity in Europe from the Atlantic to the Urals are needed urgently. This is why, no matter how much one may want to solve the problem in an "all or nothing" way, a more flexible and loose scheme of work looks more realistic - at first in less binding formats, through the restoration of trust in practical 
terms, and then by gradually creating conditions for concluding a new regional agreement that would adequately reflect changes in the military-political situation.

One of the logical starting points for that could be political reiteration of the 1997 NATO-Russia Founding Act's provisions barring additional permanent stationing of "substantial combat forces," to be accompanied by steps specifying geographical areas of stationing and determining quantitative ceilings for "substantial combat forces." Confidence-building measures with regard to new high-precision long-range non-nuclear capabilities, whose rapid development after the conclusion of the CFE Treaty has dramatically changed the military-strategic balance on the continent, and military activity associated with these capabilities, would also play an important role. The latter, in turn, may also require a serious modernization of the Vienna Document 2011.

The current arms control crisis is caused, in many ways although not entirely, not by an abundance of norms that reduces securitywhich would be the first thing to come to mind when analyzing the transformation of the world order, and the subsequent desire to get rid of these outdated norms-but, on the contrary, by their lack in areas that are not sufficiently covered.

The liberalization of the rules of counting nuclear warheads deployed on heavy bombers under the New START Treaty is an example. It became a step backwards from START I that was in force until December 2009. But the INF Treaty is perhaps the most characteristic example. It was regularly criticized by both sides for at least the last fifteen years as a "relict" and extremely stringent open-ended agreement that does not take into account modern realities (horizontal proliferation of nuclear missile technologies). But what was the result? The dissolution of the regime and the emergence of a dangerous "gray zone" of offensive arms, which affected strategic stability in the past and will affect it even more now, given the rapid development of both nuclear and conventional high-precision long-range weapons and hypersonic systems (for more details see Bogdanov, 2019).

Both sides are already discussing a possible solution in the form of looser and more flexible regional regimes at first (e.g., potentially 
trilateral in East Asia), based mainly on the transparency of the relevant weapon programs and the military activity of the parties involved. An important role can be played by an implementable refusal (in the form of political declarations or commitments) to deploy intermediate-range systems of a certain class in Europe.

This scenario is also supported by Russia's latest official proposals for a moratorium on the deployment of intermediate-range weapons in Europe, combined with confidence-building measures with regard to disputed facilities and weapons (9M729 cruise missiles and Aegis Ashore missile launchers). In the future, it would be feasible to consider the possibility of concluding regional legally binding agreements or even including intermediate-range weapons in a multilateral treaty linking them to START as part of the overall balance (Arbatov, 2020).

One of the most important tasks of arms control is to maintain crisis stability by limiting the creation and deployment of weapons that increase the potential for escalation in a military crisis. Under the current conditions of multiplying new military-technical factors, crisis stability, in fact, should be not so much strengthened as reassembled. This is especially important in new substantive areas that remain completely uncovered not only by arms control documents, but even by transparency and confidence-building measures (for example, cyber warfare).

To a certain extent, this means that everything will have to be started anew, in a way. The phases of negotiations and preparation of agreements on offensive arms that the Soviet Union and the U.S. have already successfully passed since the end of the 1960s will have to be repeated again, this time in relation to a larger number of participants and broader scope (cyber weapons, space-based weapons, non-strategic nuclear weapons, high-precision long-range weapons), as well as on the ruins of partially or completely bygone agreements (INF Treaty, CFE Treaty).

Idealistic attempts to build completely new complex universal and intrusive agreements, let alone multilateral ones, in these areas in the current situation are most likely doomed to failure. A collapse of these inflated expectations will cause deep disappointment in the process itself and will easily prompt the rejection of any meaningful work on 
the arms control track. (Such sentiments are already strong enough; suffice it to recall the 2019-2020 controversy around the collapse of the INF Treaty and the extension of the New START Treaty.) This is why developing strategic dialogue, adopting and gradually transforming realistic political commitments in "undeveloped" or "abandoned" areas would be vital for laying the groundwork for more rigid intrusive agreements. At the same time, this would make it possible not to inflate the scope of negotiations on the next legally binding START treaty, focusing instead on critical issues (Vaddi and Acton, 2020).

A "matryoshka" is perhaps the best metaphor for arms control in the modern era. The rigid core of legally binding agreements, ideologically related to the obligations of the official nuclear powers under Article 6 of the NPT (the New START Treaty and subsequent documents, as well as all others that can be concluded in a legally binding form), is necessary if the strategic stability of "central deterrence," which has become customary over so many years, is to remain a natural attribute of international relations. Replacing this stable, well-defined mode with an amorphous process of problematic dialogue will not create new benefits in the foreseeable future, but will deprive the world of a significant part of existing ones, which over the past thirty years have already begun to be seen as some kind of natural stability inherent in the international security system, without invoking the memory of war scares and nuclear risks in the late 1970s and early 1980s, and of how much effort had to be taken in order reduce them to the current level.

But the parallel development of such dialogue in the peripheral zones of the "matryoshka," on the contrary, could have a beneficial effect on the entire arms control system for both vertical (scope) and horizontal (composition of participants) expansion. This clearly offers an opportunity for a creative combination of all possible approaches, schemes, formats, and platforms. This process is also infrastructurally linked to confidence-building (with regular exchanges of views on priorities and concerns) and the preservation of de facto disintegrating or dead regimes (e.g. INF Treaty and CFE Treaty). Working solutions 
can be transferred from this process to the core for the conclusion of agreements on certain international security issues, if and when such solutions are organically worked out through strategic dialogue.

Thus, the hybrid approach to arms control, while not being something fundamentally new, during the transitional period attaches much greater significance to the horizontal and vertical development of peripheral zones as a means of ensuring additional stability of basic intrusive agreements in the increasingly complicated military-political and military-technical environment. At the same time, the peripheral zones, with their amorphous formats and lack of obligations, will not be able to assume the role of supporting structures that will have to be preserved and upgraded separately, but they can make a significant contribution to this modernization by supporting strategic dialogue and supplying mature solutions to be legally formalized in the core.

It is difficult to say how long the current doldrums can last. There is a chance that the situation will improve sooner or later and return into its familiar state in the form of an increasingly universal and legally binding disarmament process, but this will depend on whether the system of international relations is able to quickly and painlessly overcome this period of turbulence and become orderly again. In some cases, such an "emergency" solution may stay with us for many decades. After all, there is nothing more permanent than temporary.

\section{References}

Acton, J., Arbatov, A., Bin, L., Dvorkin, V., Topychkanov, P., and Zhao, T., 2017. Entanglement: Russian and Chinese Perspectives on Non-Nuclear Weapons and Nuclear Risks. Washington, DC: Carnegie Endowment for International Peace. Aladin, V., Kovalev, V., Malkov, S., and Malinetsky, G., 2013. Predely sokrashcheniya [The Limits of Reduction]. Moscow: Institut russkoi tsivilizatsii. Anthony, I., 2018. Military Dimensions of a Multipolar World: Implications for Global Governance. Strategic Analysis, 42(3), pp. 208-219.

Arbatov, A., 2018. Collapse of the World Order? Russia in Global Affairs, 16(1), pp. 160-176. 
Arbatov, A., 2019. A New Era of Arms Control: Myths, Realities and Options. Carnegie Moscow Center [online]. Available at: https://carnegie.ru/ commentary/80172 [Accessed 15 March 2021].

Arbatov, A., 2020. Trilateral Nuclear Arms Control-A Russian Assessment. In: Kuhn, U. (ed.) Trilateral Arms Control? Perspectives from Washington, Moscow, and Beijing. Research Report \#002. Hamburg: IFSH, pp. 38-67.

Batyuk, V., 2018. Smert' kontrolya nad vooruzheniyami [The Death of Arms Control]. Aktualnye problemy Evropy, 1, pp. 17-37.

Bin, L., 2011. China's Potential to Contribute to Multilateral Nuclear Disarmament. Arms Control Today [online]. Available at: https://www. armscontrol.org/act/2011-03/china\%E2\%80\%99s-potential-contributemultilateral-nuclear-disarmament [Accessed 15 March 2021].

Bogaturov, A. (ed.), 2003. Sistemnaya istoriya mezhdunarodnykh otnosheniy. Tom 3. [A Systemic History of International Relations. Vol. 3.] Moscow: NOFMO.

Bogdanov, K., 2019. Po tu storonu Dogovora RSMD: Voyenno-politicheskie posledstviya dlya Evropy [Beyond the INF Treaty: Military and Political Implications for Europe]. Sovremennaya Evropa, 90(4), pp. 140-151.

Brooks, L., 2020. The End of Arms Control? Daedalus, 149(2), pp. 84-100.

Cimbala, S., 2017. Nuclear Arms Control: A Nuclear Posture Review Opportunity. Strategic Studies Quarterly, 11(3), pp. 95-114.

Colby, E., 2018. If You Want Peace, Prepare for Nuclear War. Foreign Affairs, 97(6), pp. 25-32.

Davis, I., 2020. Global Instruments for Conventional Arms Control. SIPRI Yearbook 2020. Armaments, Disarmament and International Security. Oxford: Oxford University Press, pp. 485-501.

Dvorkin, V., 2017. Sokrashcheniye strategicheskikh vooruzhenii [The Reduction of Strategic Arms]. In: Arbatov, A., Bubnova, N. (eds.) Bezopasnost' i kontrol nad vooruzheniyami 2015-2016. Mezhdunarodnoe vzaimodeistviye $v$ bor'be $s$ globalnymi ugrozami [Security and Arms Control 2015-2016. International Cooperation in Fighting Global Threats]. Moscow: IMEMO RAN, ROSSPEN, pp. 36-47.

Ford, C., 2013. Anything but Simple: Arms Control and Strategic Stability. In: Colby, E. and Gerson, M. (eds.) Strategic Stability: Contending Interpretation. Carlisle Barracks, PA: U.S. Army War College, pp. 201-269. 
Hines, J., 1995. Soviet Strategic Intentions 1965-1985: An Analytical Comparison of U.S. Cold War Interpretations with Soviet Post-Cold War Testimonial Evidence. Ph.D. thesis. Edinburgh University (U.K.).

Inozemtsev, V. and Karaganov, S., 2005. O mirovom poryadke XXI veka [On the 21st-Century World Order]. Rossiya v globalnoi politike, 3(1), pp. 8-26.

Karaganov, S. and Suslov, D., 2019. The New Understanding and Ways to Strengthen Multilateral Strategic Stability. Moscow: Higher School of Economics.

Krauthammer, C., 1990. The Unipolar Moment. Foreign Affairs, 70(1), pp. 23-33.

Krepon, M., Wheeler, T. and Mason, S. (eds.), 2016. The Lure and Pitfalls of MIRVs: From the First to the Second Nuclear Age. Washington, DC: Henry L. Stimson Center.

Kroenig, M., 2013. Think Again: American Nuclear Disarmament. Foreign Policy, 9 March [online]. Available at: https://foreignpolicy.com/2013/09/03/ think-again-american-nuclear-disarmament/ [Accessed 15 March 2021].

Legvold, R., 2018. The Future of Nuclear Arms Control. In: Kantor, V. (ed.) Topical Issues of Nuclear Non-Proliferation. International Luxembourg Forum on Preventing Nuclear Catastrophe, pp. 26-49.

Leontyev, V., 2019. Signal doshol [The Call Has Come]. Nezavisimyoe voyennoe obozrenie, 13(1041).

Littlewood, J., 2018. Implications for the Biological and Toxin Weapons Convention. In: Crowley, M., Dango, M., and Shang, L. (eds.) Preventing Chemical Weapons: Arms Control and Disarmament as the Sciences Converge. London: Royal Society of Chemistry, pp. 69-100.

Neuneck, G., 2019. The Deep Crisis of Nuclear Arms Control and Disarmament: The State of Play and the Challenges. Journal for Peace and Nuclear Disarmament, 2(2), pp. 431-452.

Nikitin, A., 2018. Sovremenny miroporyadok: yego krizis i perspektivy [Modern World Order, Its Crisis and Prospects]. Polis. Politicheskie issledovaniya, 6, pp. 32-46.

Petrovsky, V., 2004. Strategicheskaya bezopasnost'-trebovanie XXI veka [Strategic Security as the 21st-Century Requirement]. Sovremennaya Evropa, 1, pp. 37-46.

Podvig, P., 2008. The Window of Vulnerability That Wasn't: Soviet Military Buildup in the 1970s-A Research Note. International Security, 33(1), pp. 118-138. 
Potter, W., 2001. US-Russian Relations: The Arms Control Agenda. Paris: IFRI.

Rogov, S., 2020. Novaya kholodnaya voina: posledstviya dlya rossiiskogo obshchestva [The New Cold War: Consequences for Russian Society]. Vestnik Rossiiskoi akademii nauk, 90(2), pp. 279-292.

Schelling, T. and Halperin, M., 1961. Strategy and Arms Control. New York: The Twentieth Century Fund.

Schneider, M., 2019. Trading Arms Control for Nuclear Modernization: An Old Scam. RealClearDefense, 12 July [online]. Available at: https://www. realcleardefense.com/articles/2019/06/12/trading_arms_control_for_nuclear_ modernization_an_old_scam_114499.html [Accessed 15 March 2021].

Snyder, J., 1977. The Soviet Strategic Culture: Implications for Limited Nuclear Options. Report R-2154-AF. Santa-Monica, CA: RAND Corporation.

Tertrais, B., 2010. The Illogic of Zero. The Washington Quarterly, 33(2), pp. 125 138.

Utkin, A., 2005. Mirovaya kholodnaya voina [The World Cold War]. Moscow: EKSMO, Algoritm.

Vaddi, P. and Acton, J., 2020. A ReSTART for U.S.-Russian Nuclear Arms Control: Enhancing Security Through Cooperation. Washington, DC: Carnegie Endowment for International Peace.

Vildanov, M., 2012. Sokrashchenie SNV kak strategicheskaya ulovka [Strategic Offensive Reduction as a Strategic Ploy]. Nezavisimoe voennoe obozrenie, 10 February [online]. Available at: https://nvo.ng.ru/concepts/2012-02-10/1_snv. html [Accessed 15 March 2021].

Wolfsthal, J., 2020. Why Arms Control? Daedalus, 149(2), pp. 101-115.

Yurkin, A. (ed.), 1990. Gosudarstvenny vizit Prezidenta SSSR M.S. Gorbacheva $v$ SShA, 30 maya-4 iyunya 1990 goda. Dokumenty i materialy [USSR President Mikhail Gorbachev's State Visit to the United States, May 30-June 4, 1990. Documents and Papers]. Moscow: Politizdat.

Zhao, T., 2020. Practical Ways to Promote U.S.-China Arms Control Cooperation. Carnegie-Tsinghua Center for Global Security [online]. Available at: https://carnegietsinghua.org/2020/10/07/practical-ways-to-promote-u.s.china-arms-control-cooperation-pub-82818 [Accessed 15 March 2021]. 